\title{
DISSOCIATION OF EXCITATION AND CONTRACTION IN SKELETAL MUSCLE INDUCED BY DEUTERIUM OXIDE AND DANTROLENE-SODIUM
}

\author{
Yoshimichi Yamamoto, Atsuko Suzuki, and Ken Hotta \\ Department of Physiology, Nagoya City University Medical School, \\ Mizuho-ku, Nagoya 467, Japan
}

\begin{abstract}
The effect of $\mathrm{D}_{2} \mathrm{O}$ and dantrolene- $\mathrm{Na}$ (DAN) on the electrical and mechanical responses of single muscle fiber (mouse EDL and frog semitendinosus), $\mathrm{Ca}^{2+}$ uptake and release of sarcoplasmic reticulum (SR) and contractile proteins was investigated to elucidate the coupling mechanism between depolarization and contraction.

Both agents inhibited tension development induced by depolarization and caffeine, especially the initial phase of contraction (more pronounced in fast muscle) without affecting excitation of membrane and contractile machinery. The effect of DAN can be antagonized by increasing $\mathrm{Ca}^{2+}$ concentration and lowering the temperature of the medium. $\mathrm{Ca}^{2+}$ uptake and release abilities of isolated SR were not altered significantly in DAN, but were reduced considerably in $\mathrm{D}_{2} \mathrm{O}$.

These results suggest that there is a $\mathrm{Ca}^{2+}$-mediated trigger mechanism for the rapid release of activator $\mathrm{Ca}^{2+}$ from internal storage (SR). DAN and $\mathrm{D}_{2} \mathrm{O}$ interfere predominantly the action of the site(s) of this mechanism, probably on the T-tubules. In addition, $\mathrm{D}_{2} \mathrm{O}$ decelerates $\mathrm{Ca}^{2+}$ release from SR per se.
\end{abstract}

It has been shown by KAMINER and KimurA (1972) that barnacle muscle fiber does not contract with stimulus in deuterium oxide $\left(\mathrm{D}_{2} \mathrm{O}\right)$ and the transient increase of intracellular $\mathrm{Ca}^{2+}$ associated with membrane depolarization is not detected. BEZANILLA and HoROwICZ (1975) showed the depression of fluorescence intensity (indicator of $\mathrm{Ca}^{2+}$ movement) from Nile Blue A stained frog muscle in $\mathrm{D}_{2} \mathrm{O}$. Recently, EASTwood et al. (1975), SANDow et al. (1976), and YAGI and ENDO (1976) reported the inhibition of mechanical response in intact and skinned skeletal muscle fibers. Contraction of heart muscle is also inhibited by the presence of $\mathrm{D}_{2} \mathrm{O}$ (EICHKORN et al., 1975); this situation might be brought about by depressing $\mathrm{Ca}^{2+}$ influx.

Received for publication November 4, 1976

山本喜通, 鈴木淳子, 堀田 健 
In Ringer solution containing dantrolene- $\mathrm{Na}$ (DAN, muscle relaxtant; ELLIS and CARPENTER, 1972), contraction of skeletal muscle is reduced by $80 \%$, although the excitation of membrane remains apparently normal. $\mathrm{Ca}^{2+}$ movement in muscle cell as monitored by aequorin is depressed in DAN medium (HAINAUT and DeSMEDT, 1974). Since $\mathrm{D}_{2} \mathrm{O}$ as well as DAN seem to have no direct effect on the contractile system, enzymes of cell membranes and the sarcoplasmic reticulum (SR) (HotTA and MoRAles, 1960; INOUE et al., 1975), the action of these agents may be to dissociate the coupling between excitation of cell membranes and $\mathrm{Ca}^{2+}$ release from SR. Though it is certain that the T-system plays a crucial role in the process of signal transmission from the surface to the inside of the cell in skeletal muscle, the mechanism leading to the increase of myoplasmic $\mathrm{Ca}^{2+}$ is still unknown (EBASHI, 1976). ОотA et al. (1976) suggested that entry of a small amount of $\mathrm{Ca}^{2+}$ into the cell due to depolarization of T-tubule membrane might act as a trigger for large release of $\mathrm{Ca}^{2+}$ from SR. Recent reports on the action of DAN by PutNeY and BiANCHI (1974), TAKauji et al. (1975) and Honma et al. (1976) seem to support the presence of trigger $\mathrm{Ca}^{2+}$ on the T-tubule membrane.

This idea contradicts the proposal of SANDOw et al. (1975) that depolarization of the T-tubule membrane per se is responsible for $\mathrm{Ca}^{2+}$ release from the SR.

In order to elucidate the mechanism of increase of myoplasmic $\mathrm{Ca}^{2+}$ upon stimulation, we investigated the effect of $\mathrm{D}_{2} \mathrm{O}$ and DAN on depolarization-induced contraction of skeletal muscle fibers. Although the mechanism of action of $\mathrm{D}_{2} \mathrm{O}$ and DAN may be quite different, their primary site of action should be the Ttubule membrane where the signal is transmitted into the SR. The effect of these drugs at the sub-cellular level, i.e., $\mathrm{Ca}^{2+}$ uptake, $\mathrm{Ca}^{2+}$ release and $\mathrm{Ca}^{2+}$-activated ATPase activity of SR and on the contractile element were also investigated.

The facts observed in these experiments indicate that the trigger mechanism mediated by $\mathrm{Ca}^{2+}$ located in the T-system possibly takes a part during the course of excitation-contraction coupling.

\section{MATERIALS AND METHODS}

Muscle fibers and bathing solution. The experiments were performed on the fiber bundles isolated from the ext. digitorum longus (EDL) muscle of mouse and the semitendinosus muscle of frog. The bathing medium for mouse EDL was Tyrode Ringer solution composed (in $\mathrm{mM}$ ) of $\mathrm{NaCl}, 135 ; \mathrm{KCl}, 2.65$; glucose, 5.5; $\mathrm{MgCl}_{2}, 2$; and tris-maleate, $10\left(\mathrm{pH} \mathrm{7.0)}\right.$, saturated with $95 \% \mathrm{O}_{2}$ and $5 \% \mathrm{CO}_{2}$, and that for frog semitendinosus was $\mathrm{NaCl}, 105 ; \mathrm{KCl}, 2.5$; glucose, 10; and trismaleate, $10(\mathrm{pH} 7.0)$. The concentration of $\mathrm{Ca}^{2+}$ in the solutions was adjusted by addition of concentrated $\mathrm{CaCl}_{2}$. At low concentrations of $\mathrm{Ca}^{2+}$, below $0.1 \mathrm{~mm}$, free $\mathrm{Ca}^{2+}$ in the medium was controlled by addition of EGTA taking its apparent association constant with $\mathrm{Ca}$ as $4.4 \times 10^{5} \mathrm{M}^{-1}$ (OGAwA, 1968). No correction was made for that in $\mathrm{D}_{2} \mathrm{O}$. EGTA was not used for $\mathrm{Ca}^{2+}$ concentrations above 


\section{$0.1 \mathrm{mM}$.}

DAN (supplied by Yamanouchi Pharmaceutical Corp.) was saturated in the Ringer solution by adding an excess amount; the solution was then filtered. The concentration was determined spectrophotometrically (608 for $10 \mathrm{mg} / 1$ at $390 \mathrm{~nm}$, Ellis and CARPENTER, 1974). In most cases, $13 \mathrm{mg} / 1(40 \mu \mathrm{M})$ of DAN in Ringer solution was used.

Deuterium oxide $(99.7 \%$ ) was purchased from Merck Co. and distilled once in an all glass distillation apparatus (B.P., $101^{\circ} \mathrm{C}$ ). To determine the pHD of the Ringer solution composed of $\mathrm{D}_{2} \mathrm{O}$ corresponding to the $\mathrm{pH}$ of the normal Ringer, a factor of 0.44 was added to the reading of conventional $\mathrm{pH}$ meter (MIKKELSON and NiELSEN, 1960).

Stimulation and recording of response. Stimulation of the fibers was achieved with an intracellular electrode having the impedance of 2-3 M ohms with $3 \mathrm{M}$ $\mathrm{KCl}$. The maximum current across the membrane obtained through the electrode was about $300 \mathrm{nA}$. The threshold current for excitation of the membrane was approximately $50 \mathrm{nA}$ on the average. A pair of platinum electrodes was also used for stimulation of the fiber bundles extracellularly. The membrane potential change induced by the depolarizing current was detected through the same electrode used for the intracellular stimulation utilizing the preamplifier and the ATAC-250 addscope. Tension was recorded on a polyrecorder (PMP-3004, Nihon-Kohden) through a semiconductor transducer (SP-5-12, Toyota) connected to the muscle fibers. Details of the experimental setup and method of measurement were described in an earlier report (YАмАмото et al., 1976).

Preparation of muscle model. Glycerinated muscle fibers were prepared by treating frog semitendinosus in $50 \%$ glycerol at $-20^{\circ} \mathrm{C}$ for about one week. Before use, glycerol was washed out with a solution containing $0.1 \mathrm{M} \mathrm{KCl}$ and $20 \mathrm{~mm}$ tris-maleate ( $\mathrm{pH} 7.0)$. The muscle fibers were separated into small bundles (cross section; about $0.1 \mathrm{~mm}^{2}$ or diameter; $0.3 \mathrm{~mm}$ ) and attached to the tension transducer. Tension development was initiated by addition of ATP (3 mM) in the bathing solution ( $0.1 \mathrm{M} \mathrm{KCl}, 1 \mathrm{mM} \mathrm{Mg}^{2+}, 20 \mathrm{~mm}$ tris-maleate, $\left.\mathrm{pH} 7.0\right)$.

Preparation of $S R$ and measurement of $\mathrm{Ca}^{2+}$ uptake, release and ATPase activity. Fragmented sarcoplasmic reticulum (SR) was obtained from rabbit skeletal muscle according to the method of EBASHI and LIPMAN (1962). The purified sample was suspended in a buffer containing $0.1 \mathrm{M} \mathrm{KCl}, 1 \mathrm{mM} \mathrm{MgCl}$ and $20 \mathrm{~mm}$ tris-maleate. This solution was used also for $\mathrm{Ca}^{2+}$ binding and ATPase activity measurements. $\mathrm{Ca}^{2+}$ binding of $\mathrm{SR}$ was performed in the presence of $3 \mathrm{~mm}$ ATP and $1 \mathrm{mM} \mathrm{MgCl}_{2}$ by the Millipore filtration method using ${ }^{45} \mathrm{Ca}$. Release of bound $\mathrm{Ca}^{2+}$ from SR was performed as follows: $\mathrm{Ca}^{2+}$ was loaded to $\mathrm{SR}$ in the presence of ATP and $\mathrm{Mg}^{2+}$ for $5 \mathrm{~min}$ and then the medium was diluted with the solution containing $3 \mathrm{~mm}$ EGTA instead of ATP to 20 times followed by filtration at $30 \mathrm{sec}, 1,5$, and $10 \mathrm{~min}$ after dilution. The remaining bound $\mathrm{Ca}\left({ }^{45} \mathrm{Ca}\right)$ to $\mathrm{SR}$ on the filter was measured. ATPase activity of SR was 
measured in the presence of $3 \mathrm{~mm}$ ATP, $1 \mathrm{mM} \mathrm{MgCl}_{2}$ and $\mathrm{P}_{\mathrm{i}}$ liberated from ATP was analyzed by Fiske and SubBaRow (1925) method. DAN or $\mathrm{D}_{2} \mathrm{O}$ did not interfere the colorimetric measurement of $P_{i}$ by this method.

\section{RESULTS}

Twitch and tonic responses in normal Ringer $\left(\mathrm{Ca}^{2+} ; 2 \mathrm{mM}\right)$

Both mouse EDL and frog semitendinosus muscle in normal Ringer solution responded mechanically and electrically to the intracellular stimulus, as shown in Fig. 1a, b. The responses shown here are those from single fiber although a bundle was used. When the stimulation was made by a long pulse current (1 $\mathrm{sec}$ ), the tension was maintained during the application of current (tonic response, Fig. 1c, not inhibited by TTX). In mouse EDL, the duration of action potential and contraction was considerably shorter than those of frog semitendinosus. Sometimes, mouse EDL exhibited repeated excitation upon stimulus: this phenomena caused an apparent increase of twitch tension and duration of contraction of the fibers, as shown in Fig. 1d. This repetitive excitation was abolished by increasing the $\mathrm{Ca}^{2+}$ concentration in the medium.

\section{Response in $\mathrm{D}_{2} \mathrm{O}$ and $\mathrm{DAN}$ Ringer}

In $\mathrm{D}_{2} \mathrm{O}$ Ringer $(99 \%)$ solution, the mechanical response of the frog semitendinosus upon stimulus was markedly reduced without noticeable change in resting and action potentials (Fig. 2a). The tonic response was reduced to a lesser degree than that of twitch (Fig. 2b). Upon returning to normal Ringer, the fiber recovered its mechanical response immediately (Fig. 2c). Inhibition of twitch tension varied depending on the content of $\mathrm{D}_{2} \mathrm{O}$ in the Ringer, as shown in Fig. 2d. The reduction of tension was also observed in mouse EDL muscle fiber in $\mathrm{D}_{2} \mathrm{O}$ although the tension generated was much smaller than that of frog semitendinosus muscle fiber.

In the Ringer solution containing DAN $(40 \mu \mathrm{M})$, the twitch tension of frog semitendinosus muscle fiber was reduced to 20 to $30 \%$ of that in normal Ringer. Resting and action potentials were not affected by DAN although the current required to cause the excitation of membrane increased somewhat (Fig. 3a, b). Tonic response was also inhibited, either in the presence or absence of TTX (Fig. 3c). Recovery from DAN effect could be achieved by returning the fiber to normal Ringer, but it took several minutes and in many cases, the recovery was not complete whereas in $\mathrm{D}_{2} \mathrm{O}$, both inhibition and recovery were instantaneous.

\section{Effect of temperature}

The twitch response of the fiber in $\mathrm{D}_{2} \mathrm{O}$ and DAN Ringer at temperatures from 15 to $30^{\circ} \mathrm{C}$ (mouse EDL) and 4 to $20^{\circ} \mathrm{C}$ (frog semitendinosus) were measured and compared with those in normal Ringer. The duration of action potential and contraction time of both muscles became short at high temperatures. Figure 

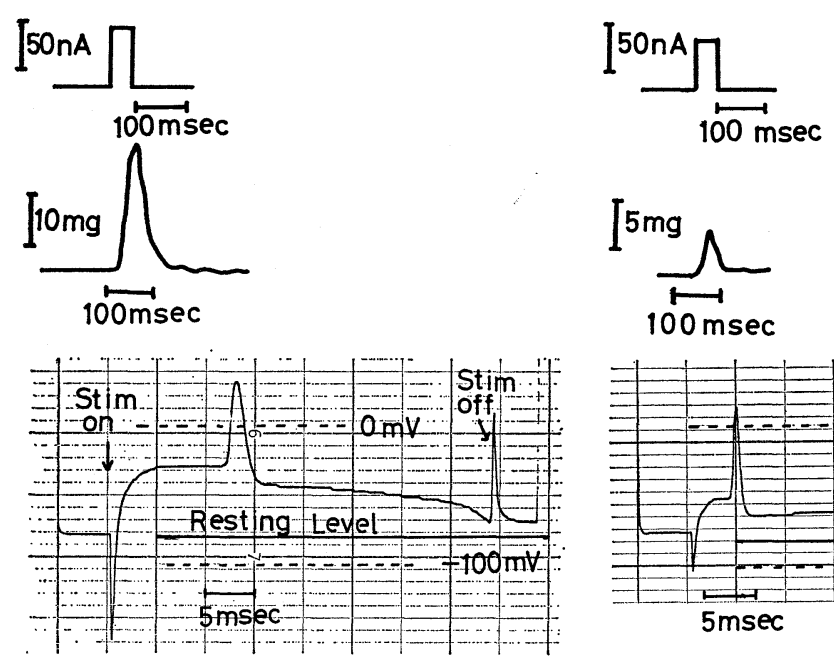

a
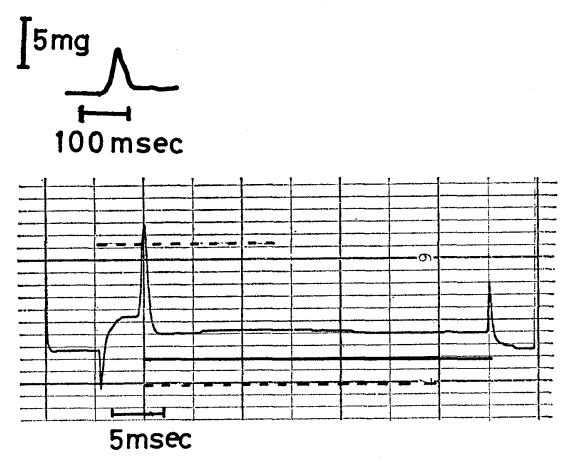

b
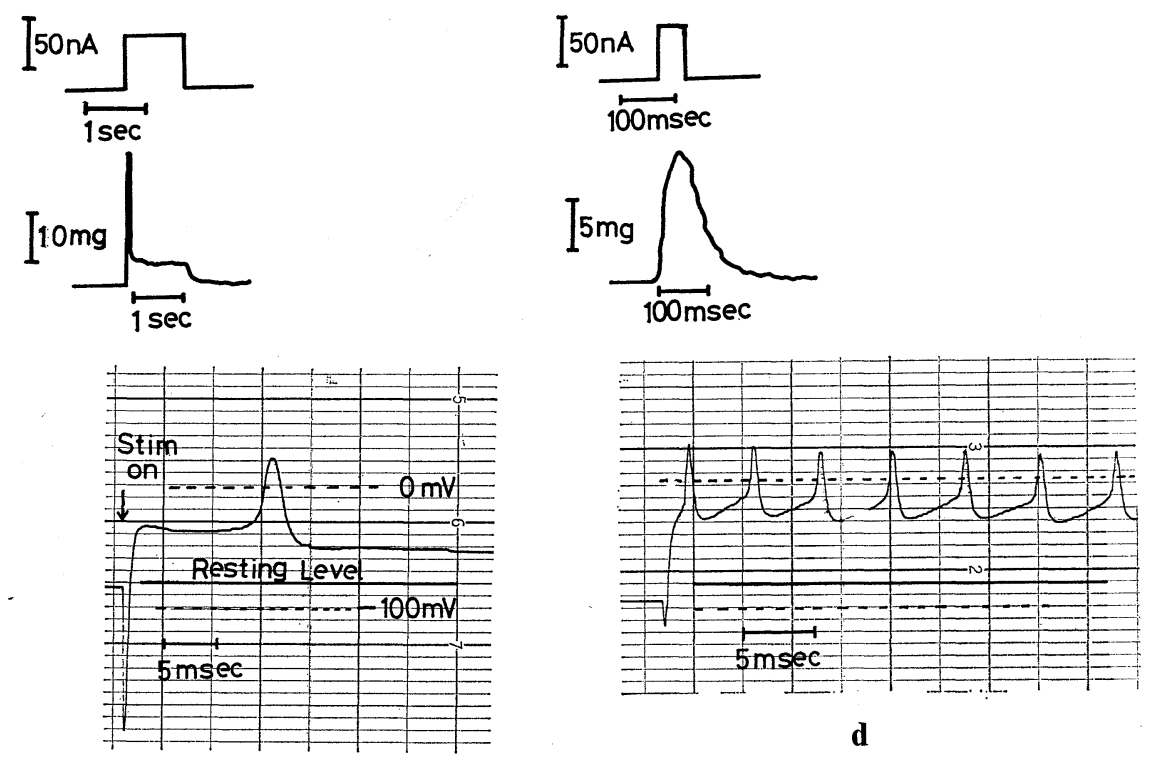

d

c

Fig. 1. Response of single muscle fiber in normal Ringer upon intracellular stimulation. Top trace, current of stimulus; middle trace, mechanical response (tension); bottom trace, electrical response (membrane potential change). (a) Twitch response, frog semitendinosus at $13^{\circ} \mathrm{C}$, (b) twitch response, mouse EDL at $28^{\circ} \mathrm{C}$, (c) twitch and tonic response, frog semitendinosus at $13^{\circ} \mathrm{C}$, (d) summation of twitch tension, mouse EDL at $28^{\circ} \mathrm{C}$. 

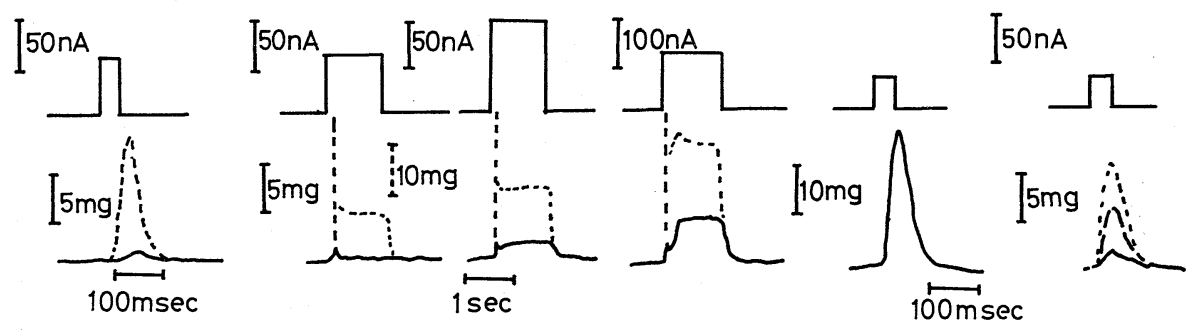

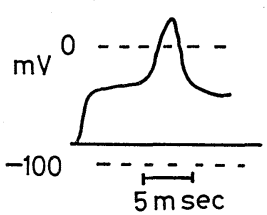

a $b$

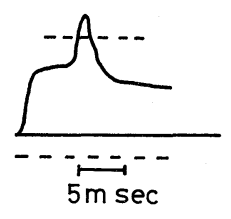

c

d

Fig. 2. Response of single muscle fiber in $\mathrm{D}_{2} \mathrm{O}$ Ringer. Frog semitendinosus at $13^{\circ} \mathrm{C}$; top, current; middle, tension; bottom, action potential. Dotted line indicates the corresponding response in normal Ringer. (a) Twitch response in $99 \% \mathrm{D}_{2} \mathrm{O}$ Ringer, (b) twitch and tonic response in $99 \% \mathrm{D}_{2} \mathrm{O}$. Note that the calibration for dotted line is $10 \mathrm{mg}$. (c) Recovery of mechanical response from $\mathrm{D}_{2} \mathrm{O}$. $10 \mathrm{sec}$ after replacement of $\mathrm{D}_{2} \mathrm{O}$ Ringer to normal Ringer. (d) Mechanical response in the Ringer containing different amount of $\mathrm{D}_{2} \mathrm{O},---, 50 \% ;--, 75 \% ;-, 90 \%$.
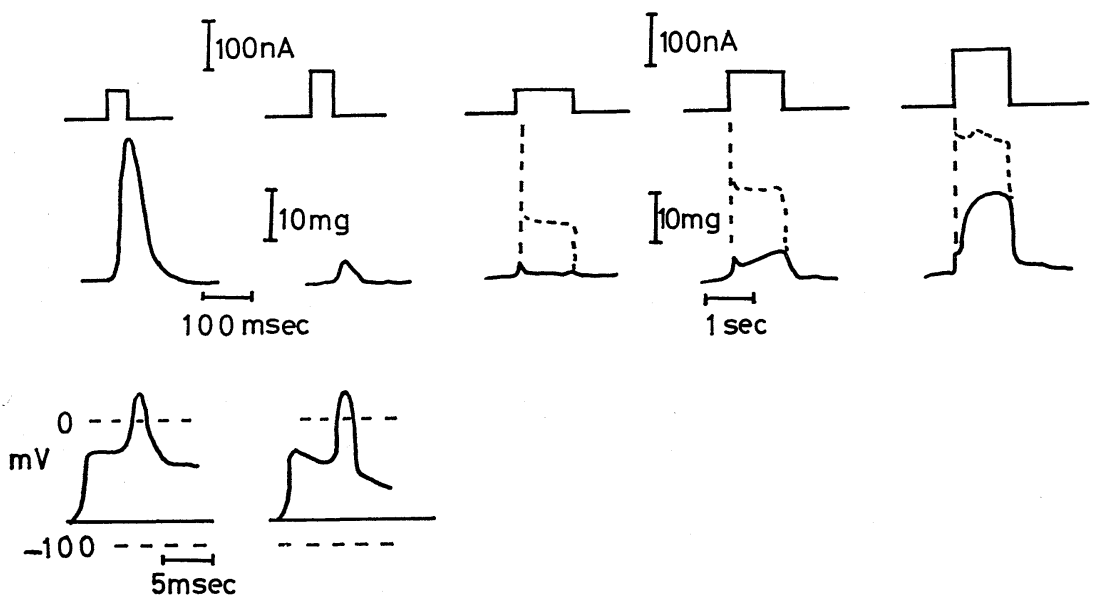

a

b

Fig. 3. Response of single muscle fiber in DAN Ringer, frog semitendinosus at $13^{\circ} \mathrm{C}$. Top, current; middle, tension; bottom, action potential, (a) Twitch response in normal Ringer, (b) twitch response in DAN Ringer (40 $\mu \mathrm{M})$, (c) twitch and tonic response in DAN Ringer. Dotted line indicates the control level. 


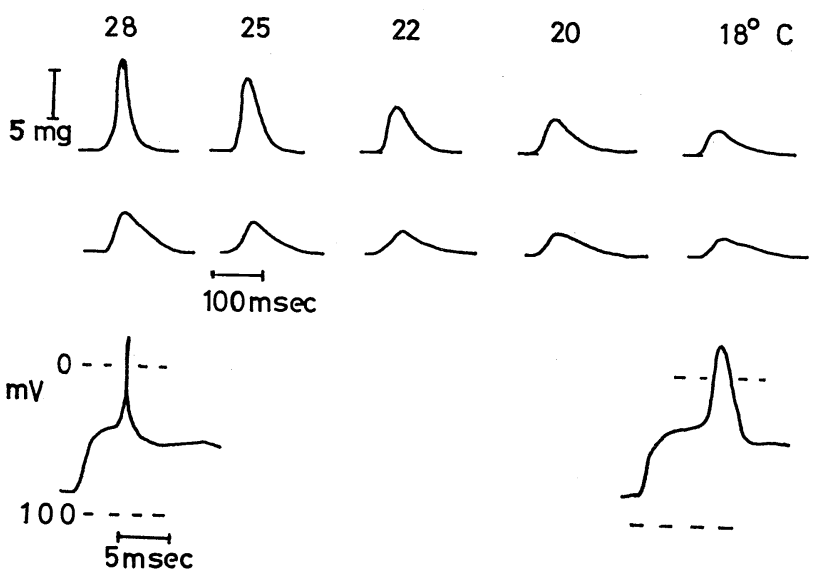

Fig. 4. Twitch response of single muscle fiber in $\mathrm{D}_{2} \mathrm{O}$ Ringer at different temperatures. Mouse EDL, intracellular stimulation $(50 \mathrm{nA}, 10 \mathrm{msec})$. Top, mechanical response in normal Ringer; middle, mechanical response in $50 \% \mathrm{D}_{2} \mathrm{O}$ Ringer; bottom, action potential. The temperature of the measurement is indicated at the top of each trace. $\mathrm{D}_{2} \mathrm{O}$ gave no effect on the action potential.

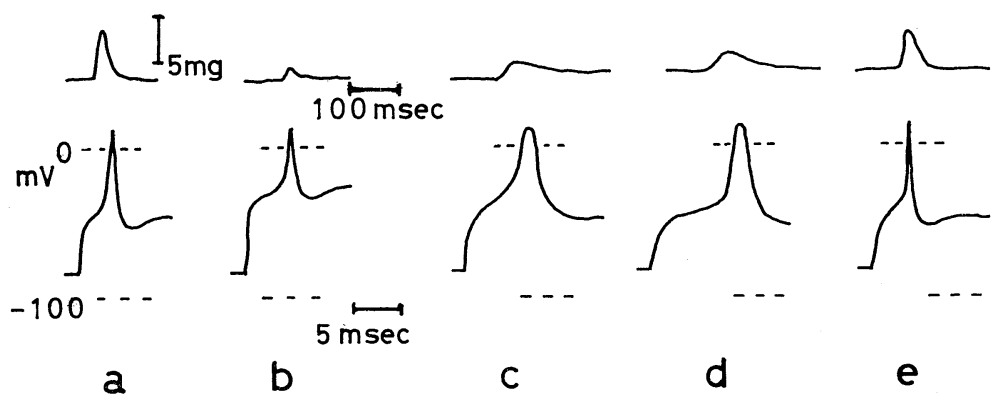

Fig. 5. Effect of temperature on twitch tension of single muscle fiber in DAN Ringer. Mouse EDL, intracellular stimulation ( $50 \mathrm{nA}, 10 \mathrm{msec})$. Upper trace, twitch tension; lower trace, action potential. (a) Response in normal Ringer at $31^{\circ} \mathrm{C}$. (b) Response in DAN Ringer at $31^{\circ} \mathrm{C}$ after 15 min incubation. (c) Response in DAN Ringer at $15^{\circ} \mathrm{C}$, after the experiment (b), the temperature of the medium was lowered from $31^{\circ} \mathrm{C}$ to $15^{\circ} \mathrm{C}$ while the fiber was resting in the same medium. It took several min to lower the temperature of the bath. (d) Response in normal Ringer at $15^{\circ} \mathrm{C}, 15 \mathrm{~min}$ after the replacement of DAN Ringer with normal Ringer. (e) Response in normal Ringer at $31^{\circ} \mathrm{C}$, after the experiment (d), the temperature of the bathing medium was raised from $15^{\circ} \mathrm{C}$ to $31^{\circ} \mathrm{C}$ to see the extent of recovery by comparing with experiment (a).

4 shows the mechanical response of mouse EDL at various temperatures in normal Ringer (top traces) and in $50 \% \mathrm{D}_{2} \mathrm{O}$ Ringer (middle traces) solutions. Apparently, twitch tension in $\mathrm{D}_{2} \mathrm{O}$ was inhibited more strongly at high temperature ranges and contraction time was prolonged at all temperatures. Action potential was not affected in the presence of $\mathrm{D}_{2} \mathrm{O}$. 
Inhibition of twitch tension by DAN was also temperature dependent. At $31^{\circ} \mathrm{C}$, DAN reduced the twitch tension developed by mouse EDL to $30 \%$ of its original value after $15 \mathrm{~min}$ incubation (Fig. 5b). When the temperature was lowered to $15^{\circ} \mathrm{C}$, the peak tension was not reduced appreciably in DAN Ringer (Fig. 5c,d).

Responses of frog semitendinosus muscle fiber to DAN were qualitatively similar to those of mouse EDL. The upper traces of Fig. 6 represent the twitch tension of fiber bundles (for this experiment, extracellular electrode was used) in normal Ringer at various temperatures. The lower traces indicate the response in DAN Ringer at the corresponding temperatures. Inhibition of twitch tension was clearly pronounced at high temperature ranges. The initial rate of tension development was decreased in the presence of DAN, but the time to peak tension was not altered.

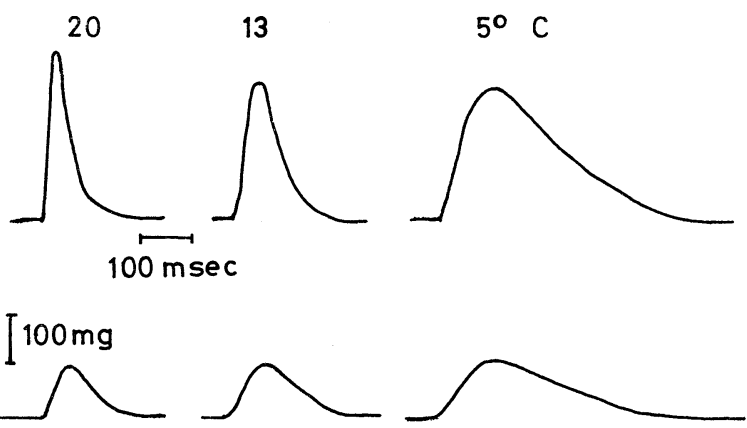

Fig. 6. Effect of DAN on twitch response at low temperature ranges, frog semitendinosus muscle fiber bundles, extracellular stimulation $(20 \mathrm{~V}, 10 \mathrm{msec})$. Upper trace, twitch tension in normal Ringer; lower trace, twitch tension in DAN Ringer $(40 \mu \mathrm{M})$. The temperature of measurement is indicated at the top of each trace.

\section{Effect of external $\mathrm{Ca}^{2+}$ concentration}

Twitch amplitude of muscle fiber was somewhat reduced in high $\mathrm{Ca}^{2+}$ Ringer, probably because of stabilization of membrane (FRANKENHAEUSER and LäNNERGREN, 1967). Also, increase of $\mathrm{Ca}^{2+}$ concentration in the medium antagonized the inhibitory effect of DAN on twitch tension, as shown in Fig. 7. The same antagonistic effect of $\mathrm{Ca}^{2+}$ in twitch response in $\mathrm{D}_{2} \mathrm{O}$ were noticed, however, to a lesser degree than those in DAN Ringer. In low $\mathrm{Ca}^{2+}$ media (less than $0.1 \mathrm{~mm}$ ), contraction of EDL was augmented at first, followed by the loss of contractility within several minutes. $\mathrm{Ca}^{2+}$ requirement for the function of mouse EDL seems to be more strict than for frog semitendinosus muscle which can respond to the stimulus in $\mathrm{Ca}^{2+}$-free medium for a considerable length of time (SANDOw et al., 1975). 


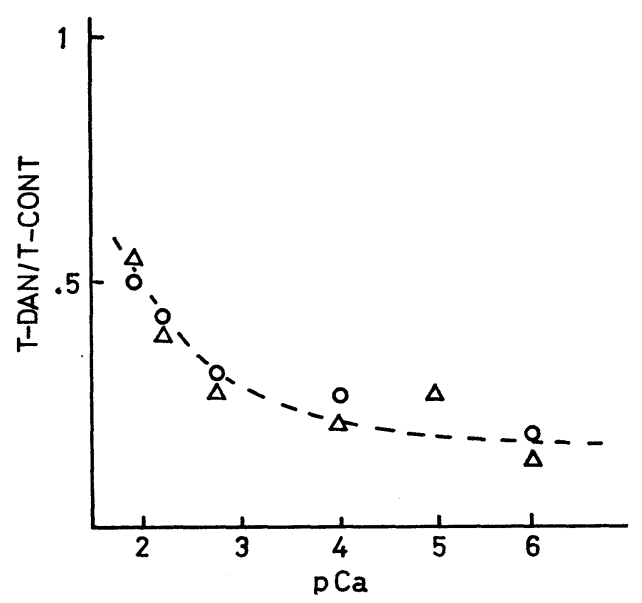

Fig. 7. Effect of external $\mathrm{Ca}^{2+}$ concentration on twitch response in DAN Ringer, mouse $\mathrm{EDL}$ at $28^{\circ} \mathrm{C}$, frog semitendinosus at $15^{\circ} \mathrm{C}$. Both fiber bundles were stimulated extracellulary $(20 \mathrm{~V}, 10 \mathrm{msec})$. The ratio of peak twitch tension in DAN (15 min incubation) and that in normal Ringer are plotted at various $\mathrm{Ca}^{2+}$ concentrations. $\triangle$, mouse EDL; O, frog semitendinosus.
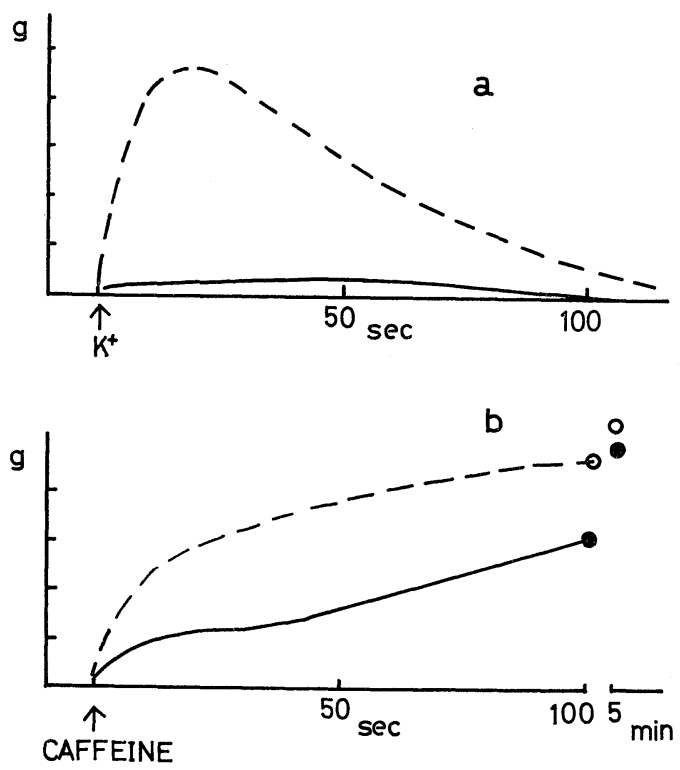

Fig. 8. Potassium and caffeine contracture of muscle in $\mathrm{D}_{2} \mathrm{O}(99 \%)$. Frog semitendinosus. Dotted line indicates the corresponding control in normal Ringer. (a) $\mathrm{K}^{+}$contracture in $110 \mathrm{mM} \mathrm{K}$ Ringer at $15^{\circ} \mathrm{C}$, (b) caffeine contracture $(5 \mathrm{~mm})$ at $15^{\circ} \mathrm{C}$. Note that the tension developed $5 \mathrm{~min}$ after the addition of caffeine reached to the same level of the control. 
$K^{+}$and caffeine contractures

Experiments on $\mathrm{K}^{+}$and caffeine induced contractures were performed on whole semitendinosus muscle of frog by placing specimens in $\mathrm{K}^{+}$Ringer $(110 \mathrm{mM})$ or Ringer containing $5 \mathrm{~mm}$ caffeine. As shown in Fig. 8a, $\mathrm{D}_{2} \mathrm{O}(99 \%)$ abolished the tension induced by high $\mathrm{K}^{+}$almost completely. The contracture induced by caffeine was also inhibited in $\mathrm{D}_{2} \mathrm{O}$ Ringer, especially in the early phase, however, tension increased gradually and after $5 \mathrm{~min}$, it reached the same level to that of control (Fig. 8b). The presence of DAN (40 $\mu \mathrm{M})$ in Ringer solution also reduced the tension development by high $\mathrm{K}^{+}$or caffeine, to a lesser degree than those in $\mathrm{D}_{2} \mathrm{O}$.

\section{ATP-induced contraction of glycerinated muscle fibers}

Glycerinated muscle fiber in the measuring medium $\left(0.1 \mathrm{M} \mathrm{KCl}, 1 \mathrm{mM} \mathrm{Mg}^{2+}\right.$, $20 \mathrm{~mm}$ tris-maleate) developed tension upon addition of ATP (3 mM), as shown in Fig. 9. In a medium made up of $99 \% \mathrm{D}_{2} \mathrm{O}$ or that containing $40 \mu \mathrm{M}$ of DAN, the fiber bundles generated tension as large as that in the control medium. Actual recording of tension was varied depending on the sizes of fiber bundles, but the maximum tension per unit cross section fell into the same ranges in all media (Fig. 9).

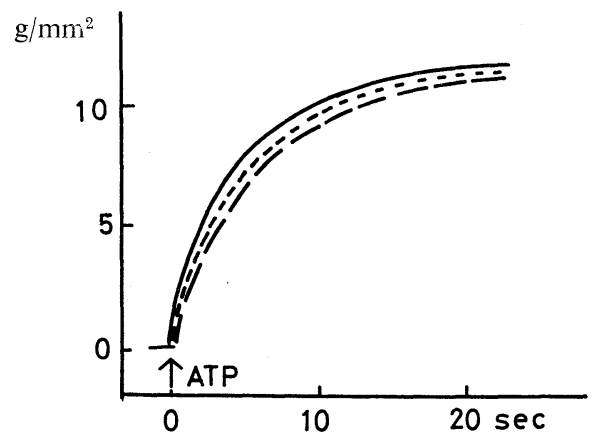

Fig. 9. ATP-induced contraction of glycerinated muscle fiber bundles; frog semitendinosus muscle fiber bundles. Medium; $0.1 \mathrm{M} \mathrm{KCl}, 1 \mathrm{mM} \mathrm{Mg}^{2+}, 20 \mathrm{~mm}$ tris-maleate ( $\mathrm{pH}$ or pHD; 7.0 ) at $25^{\circ} \mathrm{C}$. Tension was induced by addition of $3 \mathrm{~mm}$ ATP. The diameter of the bundles was checked under the microscope and tension per $\mathrm{mm}^{2}$ calculated. -, $99 \%$ $\mathrm{D}_{2} \mathrm{O}$; - -, $40 \mu \mathrm{M}$ DAN; ---, control.

$\mathrm{Ca}^{2+}$ uptake, release and ATPase activity of fragmented sarcoplasmic reticulum

Fragmented sarcoplasmic reticulum (SR) from rabbit skeletal muscle exhibited ATP-dependent $\mathrm{Ca}^{2+}$ uptake. In the control medium $\left(0.1 \mathrm{M} \mathrm{KCl}, 1 \mathrm{mM} \mathrm{Mg}^{2+}\right.$, $0.1 \mathrm{mM} \mathrm{Ca}^{2+}\left({ }^{45} \mathrm{Ca}\right), 20 \mathrm{~mm}$ tris-maleate, $\left.\mathrm{pH} 7.0\right)$ containing $1 \mathrm{~mm}$ ATP, the sample of this preparation binds about $100 \mathrm{nmol}$ of $\mathrm{Ca}^{2+}$ per $\mathrm{mg}$ of protein. The rate and the maximum $\mathrm{Ca}^{2+}$ uptake of SR in DAN medium were slightly less than those of corresponding controls, but they were not statistically significant (Fig. 10a). 


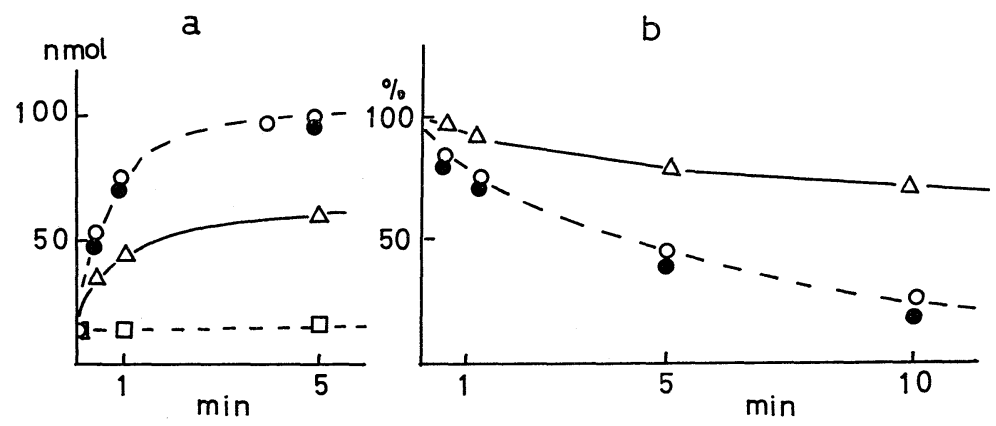

Fig. 10. $\mathrm{Ca}^{2+}$ uptake by fragmented sarcoplasmic reticulum (SR) and release, rabbit skeletal muscle. Medium; $0.1 \mathrm{M} \mathrm{KCl}, 1 \mathrm{mM} \mathrm{Mg}{ }^{2+}, 20 \mathrm{mM}$ tris-maleate (pH or $\mathrm{pHD} ; 7.0$ ) at $25^{\circ} \mathrm{C}$. (a) Time course of $\mathrm{Ca}^{2+}$ uptake, $\square$, no ATP (no difference between control, $\mathrm{D}_{2} \mathrm{O}$ and DAN); O, 1 mM APT, control; $, 1 \mathrm{~mm} \mathrm{APT,} \mathrm{DAN;} \triangle, 1 \mathrm{~mm} \mathrm{ATP,} \mathrm{D}_{2} \mathrm{O}$. (b) $\mathrm{Ca}^{2+}$ release. $\mathrm{Ca}^{2+}$ taken up in $\mathrm{H}_{2} \mathrm{O}$ with ATP for $5 \mathrm{~min}$ was taken as $100 \%$. The bound $\mathrm{Ca}^{2+}$ to SR after dilution with medium containing no ATP (0.1 mM EGTA) are plotted. $\bigcirc$, diluted with $\mathrm{H}_{2} \mathrm{O}$ medium; $\bullet$, diluted with DAN medium; $\triangle$, diluted with $\mathrm{D}_{2} \mathrm{O}(99 \%)$ medium.

On the other hand, in $99 \% \mathrm{D}_{2} \mathrm{O}$ medium, $\mathrm{Ca}^{2+}$ uptake of SR was reduced significantly, as shown in Fig. 10a. This reduction of $\mathrm{Ca}^{2+}$ uptake was not due to the irreversible change of $\mathrm{SR}$ in $\mathrm{D}_{2} \mathrm{O}$ because the pretreated $\mathrm{SR}$ with $99 \% \mathrm{D}_{2} \mathrm{O}$ took up $\mathrm{Ca}^{2+}$ to the same extent as that of original $\mathrm{SR}$ in $\mathrm{H}_{2} \mathrm{O}$.

The $\mathrm{Ca}^{2+}$ which had been loaded to the $\mathrm{SR}$ in $\mathrm{H}_{2} \mathrm{O}$ medium could be released by washout with large volumes of medium containing EGTA. When the dilution medium consisted of $\mathrm{D}_{2} \mathrm{O}, \mathrm{Ca}^{2+}$ release from SR was markedly decerelated.

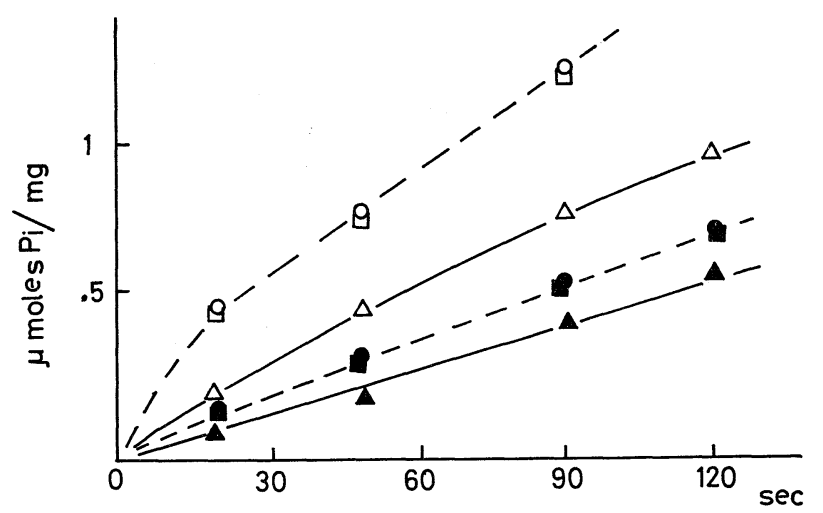

Fig. 11. Time course of liberation of $P_{i}$ from ATP by SR in the presence and absence of $\mathrm{Ca}^{2+}$ in $\mathrm{D}_{2} \mathrm{O}$ and DAN. Medium; $0.1 \mathrm{M} \mathrm{KCl}, 1 \mathrm{mM} \mathrm{Mg}{ }^{2+}, 20 \mathrm{~mm}$ tris-maleate $(\mathrm{pH}$ or pHD; 7.0) at $25^{\circ} \mathrm{C}$. O, $\bullet$, control medium; $\triangle, \boldsymbol{\Delta}, \mathrm{D}_{2} \mathrm{O}$ medium; $\square, \boldsymbol{a}, \mathrm{DAN}$ medium. Open and filled symbols indicate measurements in the presence of $\left(0.1 \mathrm{mM} \mathrm{Ca}^{2+}\right)$ and absence of (0.1 mM EGTA) $\mathrm{Ca}^{2+}$, respectively. 
There was no significant difference between $\mathrm{Ca}^{2+}$ release in control and DAN medium (Fig. 10b).

Hydrolysis of ATP by SR in the presence of $\mathrm{Mg}^{2+}$ was greatly accelerated by the addition of $\mathrm{Ca}^{2+}$ (extra splitting, HasselbaCH and MAKINOSE, 1966) in the control medium as well as in that containing DAN, i.e., DAN gave no effect on ATPase activity of SR. On the other hand, in $\mathrm{D}_{2} \mathrm{O}(99 \%)$, ATP hydrolysis of SR was decelerated, especially in early phase of reaction (Fig. 11). The disappearance of extra splitting of ATP by which the energy for $\mathrm{Ca}^{2+}$ transport may be supplied, is consistent with the reduction of ATP-dependent $\mathrm{Ca}^{2+}$ uptake ability of $\mathrm{SR}$ in $\mathrm{D}_{2} \mathrm{O}$ (Figs. 10a and 11).

\section{DISCUSSION}

$\mathrm{D}_{2} \mathrm{O}$ and DAN, as well as the other drugs which modify E-C coupling, have been used in the investigation of physiological function of muscle although their modes of action are not yet fully understood. The experiments performed here confirmed the following characteristic features of the drugs already reported (Ellis and Carpenter, 1972; Putney and Bianchi, 1974; TAKauji et al., 1975; Bezanilla and Horowicz, 1975; YAGI and Endo, 1976; SANDow et al., 1976): 1) inhibition of twitch tension without affecting the membrane potential; 2) depression of caffeine- and $\mathrm{K}^{+}$-induced contracture; and 3) no effect on the machinery for contraction. Also, the effect of DAN was most marked in twitch response of fast mammalian muscle (ElLIS and CARPENTER, 1972). DAN seems to interfere with the mechanism leading to the rapid release of $\mathrm{Ca}^{2+}$ (trigger for release of activator $\mathrm{Ca}$ ). However, most of the experiments on mammalian skeletal muscle were performed on a bundle or whole muscle, but not on single fibers, probably due to technical difficulties. We used intracellular stimulation so that the response recorded was from the single fiber in which the electrode was placed.

As reported previously (YАмАмото et al., 1976), muscle fibers exhibited twitch and tonic responses upon stimulus (Fig. 1). Both twitch and tonic responses were markedly depressed in $\mathrm{D}_{2} \mathrm{O}$ or DAN Ringer without noticeable change in the action potential although the elevation of threshold current in DAN was noticed. Since the tonic response may be attributed to the increase of myoplasmic $\mathrm{Ca}^{2+}$ utilized by depolarization of T-tubule membrane (YАмамото et al., 1976), the reduction of tonic tension by $\mathrm{D}_{2} \mathrm{O}$ and DAN suggests that $\mathrm{Ca}^{2+}$ entry through the $\mathrm{T}$-system is blocked.

Contraction of muscle fibers at high temperature is much faster than that at low temperature. Correspondingly, the duration of action potential is also temperature dependent, as illustrated in Fig. 4. In mouse EDL, the peak tension of twitch response was reduced considerably even in normal Ringer by simply lowering the temperature. However, in $\mathrm{D}_{2} \mathrm{O}$ Ringer $(50 \%)$ at low temperatures, reduction of twitch tension was not drastic (in $99 \% \mathrm{D}_{2} \mathrm{O}$, tension development was 
too small to measure), so that the relative inhibition represented as the ratio of the peak tension was apparently small at low temperature ranges. The effect of DAN was also potentiated at high temperature ranges as examined in mouse EDL and frog semitendinosus muscle fibers (Figs. 5 and 6). The time to peak tension was not altered in $\mathrm{D}_{2} \mathrm{O}$ or DAN at each temperature but the initial rate of rise was reduced. These facts indicate that some rate-limitting chemical process which is temperature-dependent may be involved in the mechanism of rapid signal transmission into the cell. $\mathrm{D}_{2} \mathrm{O}$ and DAN prevent the release of activator $\mathrm{Ca}^{2+}$ from the SR by decelerating this chemical process. The involvement of trigger $\mathrm{Ca}^{2+}$ in this mechanism was postulated by the depression of DAN effect at high external $\mathrm{Ca}^{2+}$ concentration (Fig. 7). These observations are in agreement with those of ELLIS and CARPENTER (1972) and TAKAUJI et al. (1975) that DAN inhibited predominantly the initial phasic component of $\mathrm{K}^{+}$contracture, probably mediated by trigger $\mathrm{Ca}^{2+}$ located on the T-system.

$\mathrm{K}^{+}$and caffeine contracture were inhibited by $\mathrm{D}_{2} \mathrm{O}$, much more markedly than by DAN. The difference between $\mathrm{D}_{2} \mathrm{O}$ and DAN can be explained by assuming that $\mathrm{D}_{2} \mathrm{O}$ blocks not only the trigger mechanism but also decelerates the release of activator $\mathrm{Ca}^{2+}$. In fact, this was shown in several experiments. In isolated SR, both the rate and amount of uptake and release of $\mathrm{Ca}^{2+}$ were reduced to a considerable degree in $\mathrm{D}_{2} \mathrm{O}$ medium whereas DAN gave a small effect (Fig. 10 and TAKAUII et al., 1975), although VAN WINKLE (1976) recently reported that DAN significantly suppressed the $\mathrm{Ca}^{2+}$ release from $\mathrm{SR}$ in isolated system. In the intact fibers, the intensive contraction with long duration which reflected the large release of $\mathrm{Ca}^{2+}$ from internal storage (explosive contraction in low $\mathrm{Ca}^{2+}$ medium, YАмАмото et al., 1976) was hardly observed in $\mathrm{D}_{2} \mathrm{O}$ Ringer (trace is not shown; it occurs in DAN Ringer).

SANDOw et al. (1976) characterized the effect of $\mathrm{D}_{2} \mathrm{O}$ on mechanical properties of frog muscle fibers as (1) prolongation of latency period and (2) decrease of initial rate of tension development $(d P / d t)$. They suggested that these effects were caused by (1) lowered rate and amount of $\mathrm{Ca}^{2+}$ release from SR and (2) a reduced speed of diffusion of $\mathrm{Ca}^{2+}$ to the contractile filaments in $\mathrm{D}_{2} \mathrm{O}$. YAGI and ENDO (1976) also demonstrated that the $\mathrm{Ca}^{2+}$ release in skinned fibers was reduced in $\mathrm{D}_{2} \mathrm{O}$. EASTwOOD et al. (1975), on the other hand, could not detect any effect of $\mathrm{D}_{2} \mathrm{O}$ on internal membrane system (SR) although they recognized the depression of $\mathrm{K}^{+}$contracture of crayfish muscle fibers with prolongation of relaxation time. The differences between their results and those shown here as well as those of SANDOw et al. (1976) and YAGI and ENDO (1976) probably attributed to the differences of the materials (crayfish and mammalian or frog muscle) although it seems that observation of EASTWOOD et al. (1975) can be interpreted as the reflection of retardation of $\mathrm{Ca}^{2+}$ uptake ability of $\mathrm{SR}$ in $\mathrm{D}_{2} \mathrm{O}$. Lack of enhancement of ATP hydrolysis of SR by $\mathrm{Ca}^{2+}$ from which the energy of $\mathrm{Ca}^{2+}$ transport may be supplied (HASSELBACH and MAKINOSE, 1966) in $\mathrm{D}_{2} \mathrm{O}$ is quite consistent with 
the fact that $\mathrm{SR}$ exhibits reduced $\mathrm{Ca}^{2+}$ uptake in this medium.

It is evident that from these results, there is a trigger mechanism responsible for the rapid release of activator $\mathrm{Ca}^{2+}$. However, role of $\mathrm{Ca}^{2+}$ in the trigger mechanism cannot be immediately defined as for the $\mathrm{Ca}^{2+}$-induced $\mathrm{Ca}^{2+}$ release; this mechanism may play only minor role in the E-C coupling process (THORENS and ENDO, 1975). An attractive theory presented by SCHNEIDER and CHANDLER (1973) shedded some light on this problem, i.e., the movement of charged particles in the T-system opens the $\mathrm{Ca}^{2+}$ channel in the SR membrane (CHANDLER et al., 1976). It seems that a certain chemical process mediated by $\mathrm{Ca}^{2+}$ located on $\mathrm{T}$ system, other than electrical events, is involved in the coupling between depolarization of $\mathrm{T}$-tubule membrane and $\mathrm{Ca}^{2+}$ release from $\mathrm{SR}$.

The authors thank Professor H. Sugi of Teikyo University for his comments on the manuscript. We also express thanks to Yamanouchi Pharmaceutical Corp. for providing dantroleneNa.

\section{REFERENCES}

Bezanilla, F. and Horowicz, P. (1975) Fluorescence intensity changes associated with contractile activation in frog muscle stained with Nile Blue A. J. Physiol., 246: 709-735.

Chandler, W. K., Rakowski, R. F., and Schneider, M. F. (1976) Effects of glycerol treatment and maintained depolarization on charge movement in skeletal muscle. J. Physiol., 254: $285-316$.

Eastwood, A. B., Grundfest, H., Brandt, P. W., and Reubeu, J. P. (1975) Sites of action of $\mathrm{D}_{2} \mathrm{O}$ in intact and skinned muscle fibers. J. Membr. Biol., 24: 249-263.

Ebashi, S. (1976) Excitation-contraction coupling. Ann. Rev. Physiol., 38: 293-313.

EBASH, S. and LipMAN, F. (1962) ATP linked concentration of $\mathrm{Ca}^{2+}$ in a particulate fraction of rabbit muscle. J. Cell. Biol., 14: 389-400.

Eichkorn, I., Fitzner, B., GÜNTher, J., und Pfeiffer, C. (1975) Einfluss von $\mathrm{D}_{2} \mathrm{O}$ auf Kontraktilität und Ankupplungsvorgang am Rattenpapillarmuskel. Acta Biol. Med. Germ., 34: 811-819.

Ellis, K. O. and CARPENTER, J. F. (1972) Studies on the mechanism of action of dantroleneNa. Arch. Exp. Pathol. Pharmakol., 275: 83-94.

Ellis, K. O. and CARPENTER, J. F. (1974) Mechanism of control of skeletal muscle contraction by dantrolene-Na. Arch. Phys. Med. Rehabil., 55: 362-369.

Fiske, C. H. and SubbaRow, Y. (1925) The colorimetric determination of phosphorus. $J$. Biol. Chem., 66: 375-400.

Frankenhaeuser, B. and LänNergren, J. (1967) The effect of Ca on the mechanical response of single twitch muscle fibers of xenopus laevis. Acta Physiol. Scand., 69: 242-254.

Hainaut, K. and Desmedt, J. E. (1974) Effect of dantrolene-Na on Ca movements in single muscle fibers. Nature, 252: 728-729.

Hasselbach, W. and Makinose, M. (1966) Die Calcium Pumpe der 'Erschlaffungsgrama, des Muskels und ihre Abhängigkeit von der ATP-Spaltung. Biochem. Z., 333: 518-528.

Homma, I., Kurihara, S., and SAKaI, T. (1976) Effect of dantrolene sodium on E-C coupling of frog toe muscle. Jap. J. Physiol., 26: 53-61.

Hotta, K. and Morales, M. F. (1960) ATPase activity of myosin B in $\mathrm{D}_{2} \mathrm{O}$. J. Biol. Chem., 235: pc 61-62.

Inoue, A., Fukushima, Y., and Tonomura, Y. (1975) Effect of $\mathrm{D}_{2} \mathrm{O}$ on elementary steps in the 
ATPase reactions. J. Biochem., 78: 1113-1121.

Kaminer, B. and Kimura, J. (1972) Deuterium oxide; inhibition of $\mathrm{Ca}$ release in muscle. Science, 176: 406-407.

Mikkelson, K. and Nielsen, S. O. (1960) Activity measurements with the glass electrode in $\mathrm{H}_{2} \mathrm{O}-\mathrm{D}_{2} \mathrm{O}$ mixtures. J. Phys. Chem., 64: 632-637.

OGAWA, Y. (1968) The apparent binding constant of EGTA for Ca at neutral pH. J. Biochem., 64: 255-258.

OоTA, I., KosaKa, I., and NagAI, T. (1976) Role of superficially membrane bound Ca on E-C coupling in frog skeletal muscle. Jap. J. Physiol., 26: 117-126.

Putney, J. W., Jr. and Bianchi, C. P. (1974) Site of action of dantrolene in frog sartorius muscle. J. Pharmacol. Exp. Ther., 189: 202-212.

Sandow, A., Pagala, M. K. D., and Sphicas, E. C. (1975) E-C coupling; Effect of zero Ca medium. Biochim. Biophys. Acta, 404: 163-175.

Sandow, A., Pagala, M. K. D., and Sphicas, E. C. (1976) Deuterium oxide effects on E-C coupling of skeletal muscle. Biochim. Biophys. Acta, 440: 733-743.

SCHNEIDER, M. F. and ChANDLER, W. K. (1973) Voltage dependent charge movement in skeletal muslce; a possible step in E-C coupling. Nature, 242: 244-246.

TAKauj, M., TAKahashi, N., and NaGaI, T. (1975) Effect of dantrolene-Na on E-C coupling in frog skeletal muscle. Jap. J. Physiol., 25: 747-758.

Thorens, S. and Endo, M. (1975) Ca induced Ca release and depolarization induced $\mathrm{Ca}$ release; their physiological significance. Proc. Jap. Acad., 51: 473-478.

VAN WINKLE, W. B. (1976) Ca release from skeletal muscle SR; Site of action of dantrolene-Na. Science, 193: 1130-1131.

YAGI, S. and ENDO, M. (1976) Effect of deuterium oxide on E-C coupling of skeletal muscle. J. Physiol. Soc. Jap., 38: 208-300.

Yamamoto, Y., Hasegawa, Y., and Hotta, K. (1976) Depolarization and contraction of skeletal muscle induced by intracellular stimulation. Jap. J. Physiol., 26: 333-343. 